\title{
Modulation of Brain Gene Expression during Sleep and Wakefulness: A Review of Recent Findings
}

\author{
Giulio Tononi, M.D., Ph.D. and Chiara Cirelli, M.D., Ph.D.
}

The characterization of the molecular correlates of sleep and wakefulness is essential to understand the restorative processes occurring during sleep and the cellular mechanisms underlying sleep regulation. In order to determine what molecular changes occur during the sleepwaking cycle, we have recently performed a systematic screening of gene expression in the brain of sleeping, sleep deprived, and spontaneously awake rats. Out of the $\sim 10,000$ genes screened so far, a small minority ( 0.5\%) was differentially expressed in the cerebral cortex across behavioral states. Most genes were upregulated in wakefulness and sleep deprivation relative to sleep, while only a few were upregulated in sleep relative to wakefulness and sleep deprivation. Almost all the genes upregulated in sleep, and several genes upregulated in wakefulness and sleep deprivation, did not match any known sequence.
Known genes expressed at higher levels in wakefulness and sleep deprivation could be grouped into functional categories: immediate early genes/transcription factors, genes related to energy metabolism, growth factors/adhesion molecules, chaperones/heat shock proteins, vesicle and synapse-related genes, neurotransmitter/hormone receptors, neurotransmitter transporters, enzymes, and others. Although the characterization of the molecular correlates of sleep, wakefulness, and sleep deprivation is still in progress, it is already apparent that the transition from sleep to waking can affect basic cellular functions such as RNA and protein synthesis, neural plasticity, neurotransmission, and metabolism.

(Neuropsychopharmacology 25:S28-S35, 2001). (C) 2001 American College of Neuropsychopharmacology. Published by Elsevier Science Inc.
KEY WORDS: Sleep deprivation; Microarray; Differential display

\section{GENE EXPRESSION AND THE HOMEOSTATIC REGULATION OF SLEEP}

Considering the typical duration of sleep-wake states and the time constants of their regulation (minutes to hours rather than seconds), it is plausible that gene expression in the brain is subject to significant modulations across behavioral states. For this reason, over the

From the The Neurosciences Institute, 10640 John J. Hopkins Drive, San Diego, CA 92121

Address correspondence to: Chiara Cirelli, Department of Psychiatry, U of Wisconsin at Madison, 6001 Research Park Boulevard, Madison, WI 53719, E-mail: ccirelli@med.wisc.edu past several years, we have investigated the expression of thousand of transcripts in the brain of sleeping, waking, or sleep deprived animals (Cirelli and Tononi 1998, $2000 \mathrm{a}, \mathrm{b})$. The goal of these studies is to characterize specific patterns of gene expression that distinguish sleep from wakefulness. The identification of such patterns may help us to understand the homeostatic regulation of sleep and its functional consequences.

\section{IMMEDIATE EARLY GENES EXPRESSION IN SLEEP AND WAKEFULNESS}

Our initial studies focused on the expression of the socalled immediate early genes (IEGs), which are rapidly 


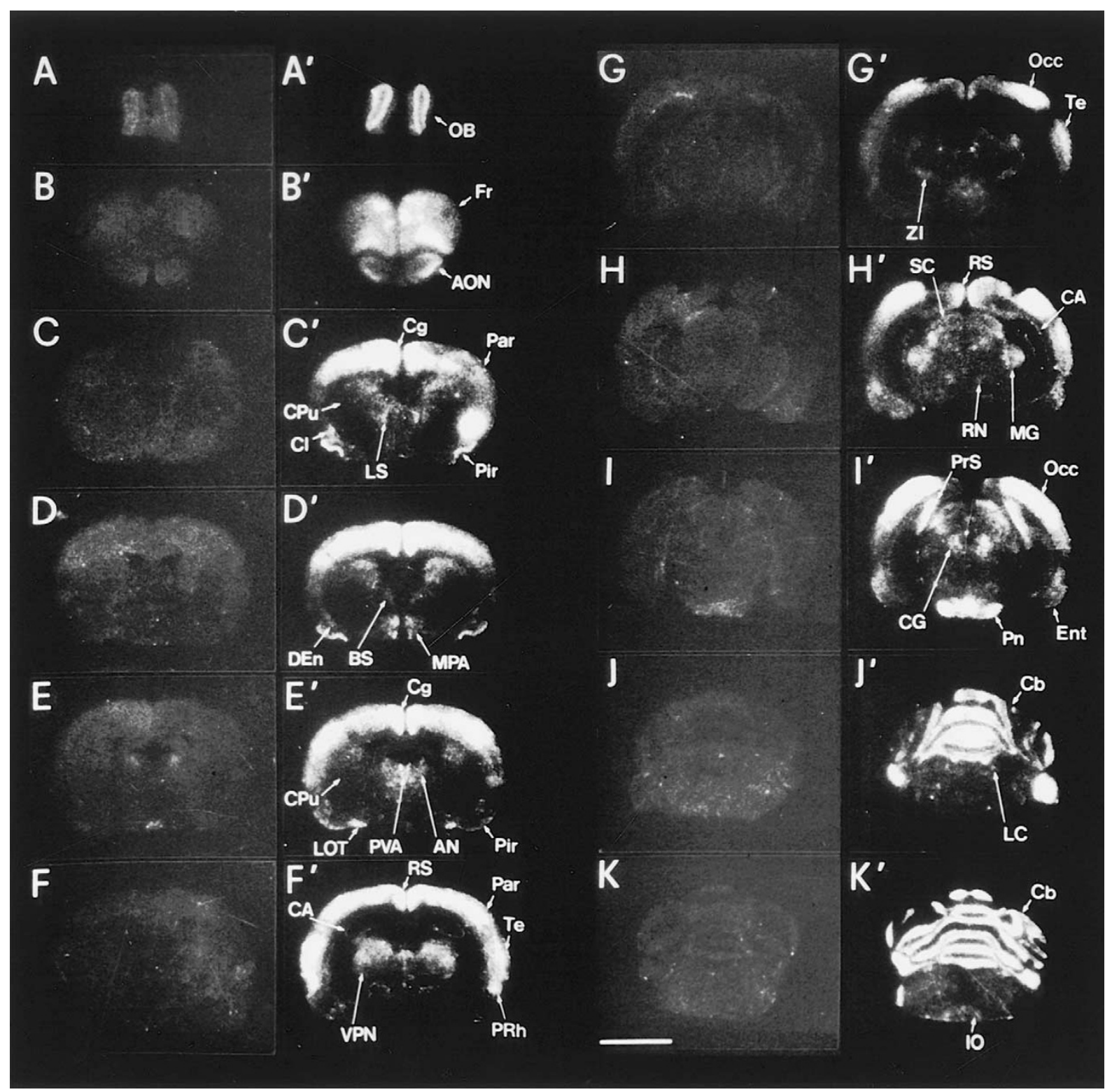

Figure 1. $c$-Fos expression in sleep and sleep deprivation. In situ hybridization shows the differential expression of $c$-fos in brain sections of a rat sacrificed after $5 \mathrm{~h}$ of spontaneous sleep $(\mathrm{A}-\mathrm{K})$ and of a rat sacrificed after $5 \mathrm{~h}$ of sleep deprivation $\left(\mathrm{A}^{\prime}-\right.$ $\left.\mathrm{K}^{\prime}\right)$. Scale bar $=5 \mathrm{~mm}$. Modified from Pompeiano et al. 1994.

induced by a large number of extracellular stimuli. The best known of such genes, $c$-fos, shows increased mRNA levels after a few minutes of stimulation, and its protein product, Fos, is synthesized shortly thereafter and can be detected for several hours. The expression of $c$-fos can thus serve as a marker of neuronal activity. In addition, $c$-fos and other IEGs function as transcriptional regulators (Sheng and Greenberg 1990) and may therefore regulate the transcription of a number of target genes that could be directly relevant to the homeostasis and functions of sleep. The results of our work (Pompeiano et al. 1994; Cirelli et al. 1995) and that of several other laboratories (reviewed in Cirelli and Tononi 2000c), has shown that the expression of IEGs is powerfully modulated by behavioral state. Specifically, the expression of $c-f o s, N G F I-A$, and other IEGs is low or absent in most brain regions if the animals had spent most of the previous $3-8 \mathrm{~h}$ asleep (Figure 1 ). On the other hand, IEGs levels are high in most of the brain if the animals had been either spontaneously awake or sleep deprived for a few hours before sacrifice (Figure 1). These results raise an important question: is the expression of IEGs merely an epiphenomenon of a particular pattern of neural activation, or does it lead to important physiological effects in the context of sleep and wakefulness? For example, if the modulation of IEGs is functionally 
significant, other, late genes should in turn be activated or deactivated in an orchestrated way during the transition from sleep to wakefulness.

\section{SYSTEMATIC ANALYSIS OF CHANGES IN GENE EXPRESSION BETWEEN SLEEP AND WAKEFULNESS}

We employed mRNA differential display and cDNA microarray technology to systematically establish the differences in gene expression that occur between sleep and wakefulness. We have compared brain gene expression after short (three hours) and sustained (eight hours) periods of sleep, spontaneous wakefulness, and sleep deprivation. We have also examined gene expression in the brain of rats chronically deprived of either total sleep or REM sleep for long periods of time (4 to 14 days). Our study focused on the cerebral cortex because it appears to be the brain region most significantly affected by sleep deprivation in humans (Horne 1988; Drummond et al. 2000). Moreover, several influential hypotheses about the functions of sleep (Maquet 1995) suggest that the cerebral cortex is the main target of the restorative effects of sleep. We estimated that, so far, we have examined $\sim 10,000$ transcripts. Because the number of genes expressed in the rat cerebral cortex is likely to range between 15,000 and 30,000 (Milner and Sutcliffe 1983), our screening is probably extensive, but not yet exhaustive.

While these studies are still in progress, several general conclusions can already be drawn, as is summarized below. We found that only a small minority of the genes expressed in the cerebral cortex $(\sim 0.5 \%)$ are up or down-regulated between sleep and wakefulness or after different periods of sleep deprivation. Most of the differentially expressed genes show higher mRNA levels after spontaneous wakefulness and/or after sleep deprivation than after sleep, while only a small minority of genes is upregulated during sleep. Most genes upregulated by $3-8 \mathrm{~h}$ of sleep deprivation are also upregulated by spontaneous wakefulness, although the increase in mRNA levels is generally more significant in the former condition. Moreover, more genes are upregulated after sustained (eight hours) or very long (days) periods of sleep deprivation than after short (three hours) periods of sleep loss. Most of the transcripts upregulated during spontaneous wakefulness and/or sleep deprivation correspond to known genes and can be grouped in few functional categories. Interestingly, different categories correspond to different periods of sleep deprivation. On the other hand, almost all the genes whose mRNA levels are higher in sleep relative to wakefulness and sleep deprivation do not match any known sequence. The only exception so far is the "sleep" gene that codes for the membrane protein E25. Even in this case, however, the function of this protein is unknown.

\section{GENES WHOSE EXPRESSION INCREASES AFTER SHORT PERIODS (3 H) OF SPONTANEOUS WAKEFULNESS AND SLEEP DEPRIVATION}

Two classes of genes show prominent changes after three hours of wakefulness or sleep deprivation: IEGs/transcription factors and mitochondrial genes encoded by the mitochondrial genome (Cirelli and Tononi 1998, 2000b; Table 1). The IEGs group includes Arc, c-fos, NGFI- $A$, the rat homolog of the human Zn-15 related zinc finger ( $r l f$ ) gene, which has been implicated in transcriptional regulation, and AA117313, probably similar to the human global transcription activator SNF2/SWI2. In addition to $A r c$ and NGFI-A (which are upregulated after both $3 \mathrm{~h}$ and $8 \mathrm{~h}$ of wakefulness and sleep deprivation), other IEGs/transcription factors are induced after sustained $(8 \mathrm{~h})$ periods of sleep loss (Cirelli and Tononi 2000a). They include CHOP, IER5, NGFI-B, N-Ras, and Stat3. Many of these genes may play a role in promoting gene transcription during wakefulness and may be involved in triggering the expression of other "late" genes such those identified after long periods of sleep loss.

Three genes coded by the mitochondrial genome were found to be induced by short periods of wakefulness and sleep deprivation: subunit I of cytochrome $C$ oxidase, subunit 2 of NADH dehydrogenase, and $12 \mathrm{~S}$ rRNA. The rapid regulation in the expression of mitochondrial genes in response to being awake for three hours was unexpected. Cytochrome $\mathrm{C}$ oxidase is the terminal enzyme of the respiratory chain, and plays a crucial role in the regulation of oxidative metabolism (Wong-Riley et al. 1997). This enzyme is made up of several subunits, some of which (e.g. subunit I) are coded by the mitochondrial genome, while others (e.g. subunit IV) are coded by the nuclear genome. Interestingly, changes in mRNA levels between sleep and wakefulness involve only the mitochondrial genes coded by the mitochondrial genome and not those coded by the nuclear genome. Mitochondria seem to contain excess amounts of nuclear-encoded cytochrome $C$ oxidase subunits. Changes in neuronal activity and energy demand affect the transcription of mitochondrially encoded subunits of cytochrome $\mathrm{C}$ oxidase more quickly and more significantly than that of the nuclear subunits (WongRiley et al. 1997). Thus, it is the synthesis of mitochondrially encoded subunits, followed by the holoenzyme assembly, that is governed by dynamic local energy needs. Cerebral glucose is almost exclusively metabolized through mitochondrial oxidative phosphorylation and glucose metabolism is $20-30 \%$ higher in wakefulness than in nonREM sleep in several species, including the rat (Ramm and Frost 1983). The increased expression of mitochondrial genes after three hours of wakefulness suggests a previously unsuspected mechanism by which neurons and/or glia can adapt to the in- 
Table 1. Gene Expression Analysis

\begin{tabular}{|c|c|c|c|}
\hline & 3 hours $W$ and SD rat & 8 hours $W$ and SD rat & $\begin{array}{l}\text { 3-11 hours W and SD } \\
\text { Drosophila Melanogaster }\end{array}$ \\
\hline $\begin{array}{l}\text { Immediate early genes / } \\
\text { transcription factors }\end{array}$ & $\begin{array}{l}\text { Arc (Arg 3.1) } \\
\text { c-fos } \\
\text { NGFI-A } \\
\text { Related to rlf } \\
\text { Related to SNF2/SW12 }\end{array}$ & $\begin{array}{l}\text { Arc (Arg 3.1) } \\
\text { CHOP } \\
\text { IER5 } \\
\text { NGFI-A } \\
\text { NGFI-B } \\
\text { N-Ras } \\
\text { Stat3 }\end{array}$ & \\
\hline $\begin{array}{l}\text { Energy metabolism/ } \\
\text { Energy balance }\end{array}$ & $\begin{array}{l}\text { Cytochrome C oxidase } \\
\text { subunit I } \\
\text { NADH dehydrogenase } \\
\text { subunit } 2 \\
12 \mathrm{~S} \text { rRNA }\end{array}$ & $\begin{array}{l}\text { Glucose transporter type I (Glut1) } \\
\text { Vgf }\end{array}$ & $\begin{array}{l}\text { Cytochrome } \mathrm{C} \text { oxidase } \\
\text { subunit I }\end{array}$ \\
\hline Novel genes & $\begin{array}{l}\text { Rat homologue of human } \\
\text { KIAA0313 } \\
\text { Unknown }(n=6)\end{array}$ & Unknown $(n=8)$ & \\
\hline $\begin{array}{l}\text { Growth factors/ } \\
\text { Adhesion molecules }\end{array}$ & & $\begin{array}{l}\text { BDNF } \\
\text { TrkB receptor } \\
\text { F3 }\end{array}$ & \\
\hline $\begin{array}{l}\text { Chaperones/ } \\
\text { Heat shock proteins }\end{array}$ & & $\begin{array}{l}\text { BiP } \\
\text { ERP72 } \\
\text { GRP75 } \\
\text { HSP60 } \\
\text { HSP70 }\end{array}$ & $\mathrm{BiP}$ \\
\hline $\begin{array}{l}\text { Vesicle- and } \\
\text { Synapse-related }\end{array}$ & & $\begin{array}{l}\text { Chromogranin C } \\
\text { Synaptotagmin IV }\end{array}$ & \\
\hline Receptors & & $\begin{array}{l}\text { Adrenergic } \alpha_{1 \mathrm{~A}} \\
\text { Adrenergic } \beta_{2} \\
\text { GABA }_{\mathrm{A}} \beta_{3} \\
\text { Glutamate NMDA 2A } \\
\text { Glutamate AMPA GLUR2 } \\
\text { Glutamate AMPA GLUR3 } \\
\text { Nicotinic } \beta_{2} \\
\text { Thyroid hormone TR } \beta\end{array}$ & \\
\hline Transporters & & $\begin{array}{l}\text { Glutamate/aspartate transporter } \\
\mathrm{Na}^{++} / \mathrm{Cl}^{-} \text {dependent neurotrans- } \\
\text { mitter transporter (NTT4/Rxt1) }\end{array}$ & \\
\hline Enzymes & & $\begin{array}{l}\text { Aryl sulfotransferase } \\
\text { c-JunN-terminal Kinase } 1 \text { (JNK1) } \\
\text { Serum/glucocorticoid-induced } \\
\text { serine/threonine kinase (SGK1) }\end{array}$ & $\begin{array}{l}\text { Arylalkylamine } \mathrm{N} \text {-acetyl- } \\
\text { transferase } \\
\text { (DAT) }\end{array}$ \\
\hline Others & & $\begin{array}{l}\text { Calmodulin } \\
\text { Cyclin D2 (Vin-1) } \\
\text { LMO-4 } \\
\text { Metallothionein } 3\end{array}$ & \\
\hline
\end{tabular}

creased metabolic demand of wakefulness relative to sleep. The functional role of this mitochondrial upregulation is supported by the recent finding that the expression of subunit I of cytochrome C oxidase increases after periods of wakefulness also in species, such as the fruit fly, that are phylogenetically very distant from the rat (Table 1). Indeed, in a completely independent gene screening project, we found that subunit I of cytochrome $\mathrm{C}$ oxidase mRNA levels are higher after periods of wakefulness and sleep deprivation relative to comparable periods of sleep-like behavior in the brain of Drosophila melanogaster (Shaw et al. 2000).

\section{GENES WHOSE EXPRESSION INCREASES AFTER SUSTAINED PERIODS (8 H) OF SPONTANEOUS WAKEFULNESS AND SLEEP DEPRIVATION}

The mitochondrial response to waking is a transient one because neither the mitochondrial genes coded by the mitochondrial genome, nor those coded by the nuclear genome are upregulated after eight hours of spontaneous wakefulness or sleep deprivation relative to eight hours of sleep. However, although mitochondrial transcripts revert to baseline levels, some other genes re- 
lated to energy metabolism are markedly upregulated after eight hours of wakefulness (Table 1). One of these genes is Glut1, one of the major glucose transporters responsible for the transfer of glucose from blood to neurons and glia. Thus, Glut1 induction may represent another mechanism employed by the brain to respond to the increased energy requirements of the waking state.

Several heat shock proteins and molecular chaperones such as HSP60, HSP70, and BiP show higher mRNA levels after sustained periods of wakefulness. $\mathrm{BiP}$, the major chaperone of the endoplasmic reticulum (ER), associates with nascent glycoproteins and secretory polypeptides during assembly in the ER and retain them in an assembly-competent shape. Increases in mRNA and/or protein levels of BiP and heat shock proteins occur during stress conditions (e.g. ischemia, severe glucose deprivation, $\mathrm{Ca}^{++}$depletion) that may cause the accumulation of unfolded or malfoded proteins in cells (see Cirelli and Tononi 2000a for refs). In these abnormal conditions Bip may target unfolded proteins for degradation or participate in their refolding. The finding that molecular chaperones and heat shock proteins are induced in a completely physiological condition, i.e. during spontaneous wakefulness, was also unexpected. The events responsible for BiP induction are still unclear, but an increase in protein synthesis, notably of proteins that require assembly in the ER, could play a role. The Aplysia homolog of BiP, for instance, is induced after long-term sensitization training, and has been hypothesized to play a role in the folding of newly synthesized proteins involved in synaptic plasticity (Kuhl et al. 1992). Despite the fact that the role of BiP induction during wakefulness is still unknown, its functional importance is once again supported by the finding that BiP mRNA levels are induced after periods of wakefulness and sleep deprivation in the brain of Drosophila melanogaster (Shaw et al. 2000; Table 1).

Another major group of genes upregulated after eight hours of wakefulness includes components of the presynaptic and postsynaptic neurotransmission machinery, such as vesicle and synaptic-related genes, subunits of several neurotransmitter receptors, both excitatory and inhibitory, and neurotransmitter transporters. The finding that AMPA receptor subunits GluR2 and GluR3 mRNA levels are higher after spontaneous wakefulness and sleep deprivation relative to sleep is particularly intriguing. The number and density of AMPA receptors at the postsynaptic membrane has been shown to be regulated by synaptic activity, and endocytosis and exocytosis of AMPA receptors regulate synaptic plasticity. Moreover, in the adult brain in vivo, long-term potentiation and long-term depression are associated with increases and decreases, respectively, of protein levels of GluR1 and GluR2 (Heynen et al. 2000). Thus, the upregulation of components of the presynaptic and postsynaptic neurotransmission machinery may represent a general compensatory response of the brain to the increased synaptic neurotransmission during wakefulness relative to sleep. In addition, the induction of at least some of these genes, such as GluR1 and GluR2, may more specifically mediate the occurrence of plastic phenomena during wakefulness.

In this regard, it is important to emphasize that, irrespective of the category in which they are listed, several of the genes upregulated in wakefulness and sleep deprivation relative to sleep have been implicated in the molecular mechanisms of neural plasticity. This is the case not only for the genes coding for GluR1 and GluR2, but also for those coding for several IEGs (Arc, c-fos, CHOP, NGFI-A), as well as for the growth factor BDNF and its receptor TrkB, the adhesion molecule F3, BiP, synaptotagmin IV, calmodulin, and a few others. Overall, our data suggest that the transcription (and possibly translation) of plasticity-related genes is favored during wakefulness relative to sleep.

\section{GENE EXPRESSION IN SLEEP AND WAKEFULNESS AND THE NORADRENERGIC SYSTEM}

Many transcripts upregulated during wakefulness are induced diffusely in the cerebral cortex and in many other brain regions. We hypothesized that a key factor responsible for their induction might be the level of activity of neuromodulatory systems such as the noradrenergic and the serotoninergic systems. These systems project diffusely to most of the brain and regulate gene expression. Moreover, their activity is strictly state-dependent.

During sleep, locus coeruleus neurons fire regularly at very low rates, whereas during wakefulness they fire at higher rates and emit phasic, short bursts of action potentials in response to salient events (Aston-Jones and Bloom 1981a). Norepinephrine released diffusely by these neurons over large portions of the brain enhances information transmission and promotes attentive processes by increasing $\gamma$ activity in the EEG (Cape and Jones 2000 and refs therein). Norepinephrine can enable various forms of activity-dependent synaptic plasticity and can stimulate gene transcription. To assess the role of the noradrenergic system in the induction of gene expression during wakefulness, we used rats whose behavior and brain electrical activity were continually monitored and in which the left locus coeruleus was lesioned (Cirelli et al. 1996; Cirelli and Tononi 2000b). Thus, when these animals were awake, norepinephrine would be released only on the right side. The rats with unilateral locus coeruleus lesions behaved normally and showed normal amounts of sleep and wakefulness. Furthermore, as demonstrated by EEG analysis, brain electrical activity seemed normal and essentially indistinguishable between the right and the left side of their 


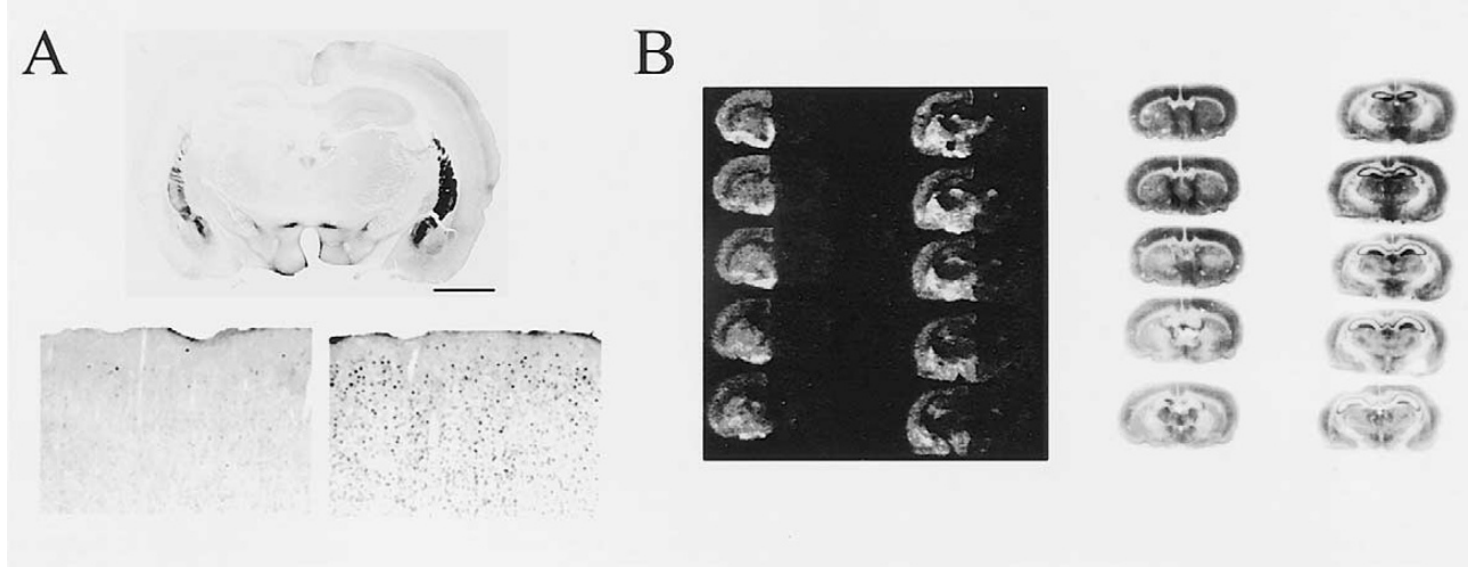

Figure 2. c-Fos expression in the cerebral cortex after lesions of the noradrenergic system of the locus coeruleus and of the serotoninergic system of the dorsal raphe. Panel A (upper image): Coronal brain section of a rat in which the left locus coeruleus was destroyed by a local injection of the neurotoxin 6-hydroxydopamine. Tyrosine hydroxylase immunostaining, used to identify noradrenergic neurons and fibers, shows the almost complete depletion of noradrenergic fibers in the left cerebral cortex and hippocampus two weeks after the lesion. The noradrenergic innervation on the right side of the brain is intact. Scale bar $=2 \mathrm{~mm}$. Panel A (lower images): Fos immunostaining in a coronal section of parietal cortex adjacent to that shown in the upper panel: after $3 \mathrm{~h}$ of sleep deprivation, Fos expression is high on the intact side (lower right), but it is as low as in sleep on the side where the noradrenergic innervation had been destroyed (lower left). Panel B (left image): After unilateral lesion of the serotoninergic system of the dorsal raphe, citalopram binding shows that the serotoninergic innervation of the cerebral cortex is destroyed on the lesioned (right) side but it is intact on the unlesioned (left) side. In the same rat, (right image) $c$-fos mRNA levels after $3 \mathrm{~h}$ of sleep deprivation do not differ between left and right side.

brain. The expression of $c$-fos, NGFI-A, P-CREB, Arc, and $B D N F$ after these animals had been awake for several hours was high on the right side, as expected. However, on the left side in which the locus coeruleus had been lesioned, the expression of these genes was abolished or greatly reduced (Figure 2, Panel A). In other words, the side of the brain depleted of nor-epinephrine appeared similar to that of a rat who had been asleep instead of awake. Thus, if the noradrenergic system is lesioned, waking behavior associated with a normal low-voltage fast activity EEG is not accompanied by the induction of molecular markers of plasticity such as c-fos, NGFI-A, P-CREB, Arc, and BDNF, suggesting that the activation of the EEG can be completely dissociated from the activation of gene expression. These findings may have several implications concerning neural plasticity, learning, and memory. The reduced expression of plasticity-related genes due to the reduced firing of locus coeruleus neurons may be a key factor determining why the ability to learn and remember new material is impaired during sleep. This finding may also help explaining why we do not remember most of our dreams, despite the fact that brain activity in REM sleep, the stage of sleep more associated with vivid dreams, is very similar to that of alert wakefulness.

Like locus coeruleus cells, serotoninergic neurons of the dorsal raphe also fire at higher levels during wakefulness and decrease their firing during sleep (McGinty and Harper 1976). However, in sharp contrast to noradrenergic neurons, dorsal raphe cells are activated during repetitive motor activity such as locomoting, grooming, or feeding and are inactivated during orientation to salient stimuli, (Jacobs and Fornal 1999). Concurrently, activation of the serotoninergic system inhibits information processing in various sensory pathways (Jacobs and Fornal 1999) and reduces $\gamma$ activity in the EEG (Cape and Jones 2000). In rats in which dorsal raphe neurons were unilaterally lesioned, it was found that $c$-fos (Figure 2B), NGFI-A, P-CREB, Arc, and BDNF expression was not affected, either during wakefulness or during sleep (Tononi et al. 2000). Thus, the dorsal raphe does not play a crucial role in brain gene expression during wakefulness.

\section{GENES INDUCED AFTER LONG PERIODS (4-14 DAYS) OF SLEEP DEPRIVATION}

Eight hours of sleep deprivation lead to a 2-fold increase in the expression of aryl sulfotransferase (Cirelli and Tononi 2000a; Table 1). Most significantly, aryl sulfotransferase was found to be induced even more markedly after several days than after several hours of sleep deprivation (Cirelli and Tononi 1999; Figure 3A). The progressively stronger induction of aryl sulfotransferase is the first demonstration of a molecular response 

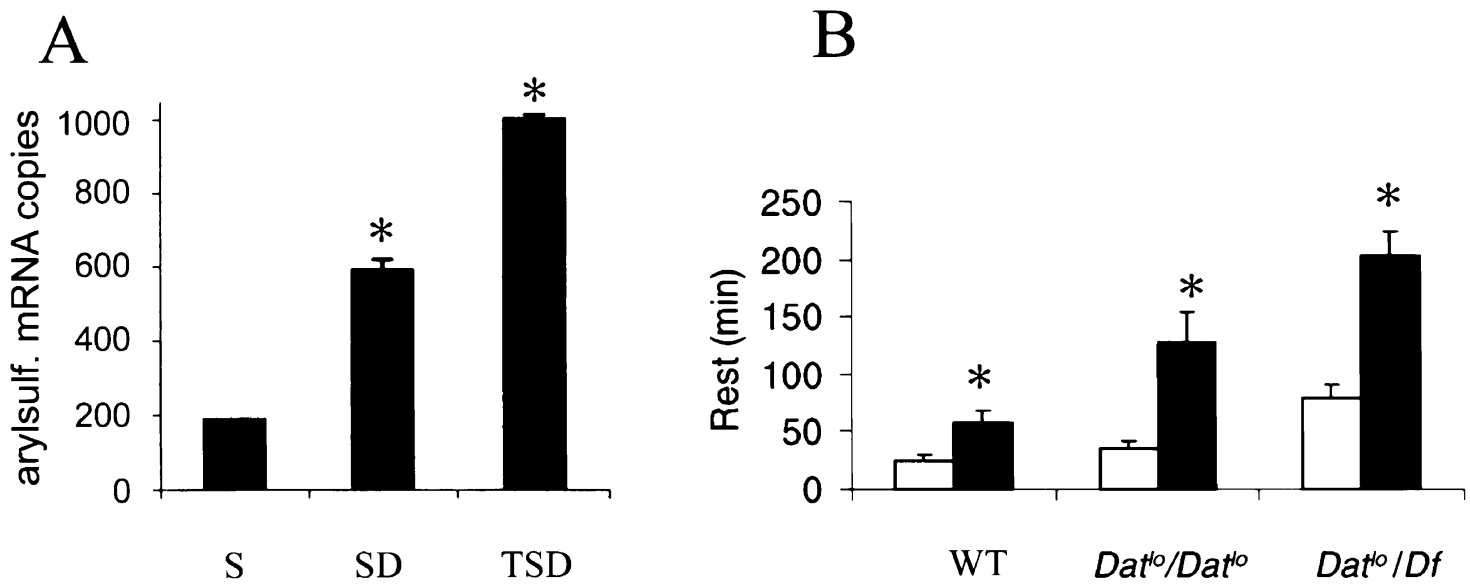

Figure 3. Catabolism of catecholamines and sleep deprivation. A. Differential expression of aryl sulfotransferase in the cerebral cortex of sleeping rats (S), rats sleep deprived for $8 \mathrm{~h}$ (SD), and rats sleep deprived for 4-14 days (TSD) using the disk-over-water method. mRNA levels of aryl sulfotransferase were measured using real-time quantitative PCR. The values on the ordinate refer to the number of mRNA copies $\left({ }^{*} p<.01\right.$, ANOVA; comparison between S and SD and between S and TSD). B. Rest rebound in $D a t^{10} / \mathrm{Dat}^{\mathrm{lo}}$ and $D a t^{l^{\circ}} / \mathrm{Df}$ flies during the first $6 \mathrm{~h}$ of recovery after $12 \mathrm{~h}$ of rest deprivation. Rest is expressed as increase (solid bars) over baseline (open bars) values during the first $6 \mathrm{~h}$ of the light period ( ${ }^{*} p<.005$; Wilcoxon test). Modified from Shaw et al. 2000.

in the brain that is proportional to the duration of sleep loss. Aryl sulfotransferase is responsible in the brain for the sulfonation of norepinephrine, dopamine and, to a lesser extent, serotonin. Aryl sulfotransferase induction during sleep deprivation may therefore constitute a homeostatic response to the uninterrupted activity of the central noradrenergic system during wakefulness. This notion is again strengthened by the evidence of converging molecular correlates recently obtained in Drosophila (Shaw et al. 2000). Rest deprivation in Drosophila is associated with an increased expression of arylalkylamine $\mathrm{N}$-acetyltransferase (Dat), an enzyme implicated in the catabolism of monoamines and functionally related to aryl sulfotransferase (Table 1). Thus, an important function of sleep may be that of counteracting the effects of continued monoaminergic discharge. If this is true, an impaired catabolism of monoamines should result in an increased need for sleep. To begin testing this hypothesis, we examined a Drosophila mutant in which the transcriptional level and activity of the Dat enzyme is deficient $\left(D a t^{l o}\right)$. Flies homozygous for the Dat $t^{l o}$ mutation do not differ from wild-type flies in the percentage and circadian distribution of rest and wakefulness and show normal amounts and patterns of activity. However, relative to wild-type flies, homozygous Dat flies show an increased rest rebound after $12 \mathrm{~h}$ of rest deprivation (Figure 3B). Moreover, $D a t^{\text {lo }} / \mathrm{Df}$ flies, in which the activity of the Dat enzyme is even lower than in $\mathrm{Dat}^{\text {lo }} / \mathrm{Dat}^{\mathrm{lo}}$ flies, show an even greater and more prolonged rest rebound after rest deprivation (Figure $3 \mathrm{~B}$ ). Thus, the more severely mutant the fly is at the Dat locus, the greater the rest rebound, suggesting that the ac- cumulation of monoamines in the brain may trigger sleep homeostasis.

\section{CONCLUSIONS}

Distinctive categories of genes change their expression in the brain in response to the transition from sleep to wakefulness, as well as after sleep deprivation. Thus, sleep and wakefulness differ not only in terms of behavior, metabolism, and neuronal activity, but also in terms of brain gene expression. Until now, almost all the genes expressed at higher levels during sleep do not correspond to known sequences. On the other hand, most of the genes that are upregulated after periods of spontaneous wakefulness and sleep deprivation are known and can be grouped into several functional categories: immediate early genes/transcription factors, genes related to energy metabolism, growth factors and adhesion molecules, chaperones and heat shock proteins, vesicle and synapse-related genes, neurotransmitter receptors, transporters, enzymes, and others. This suggest that several basic cellular functions are affected by the arousal state of the animal. The increase in the expression of genes regulating mitochondrial activity and glucose transport may underlie a compensatory response of the brain to the increased metabolic demand of wakefulness. The high expression during wakefulness of genes related to neurotransmission and synaptic activity can also be part of a compensatory response. Moreover, many of the genes upregulated during wakefulness and sleep deprivation relative to sleep are involved 
in neural plasticity, suggesting that plastic changes, in as much as they require the induction of genes, occur during wakefulness rather than during sleep. Several heat shock proteins and chaperones involved in protein folding and endoplasmic reticulum functions also show higher expression in wakefulness than in sleep. The analysis of the genes induced by long-term sleep deprivation is still in progress, but one transcript whose expression increases in proportion to the duration of wakefulness has already been identified. This transcript codes for the enzyme aryl sulfotransferase involved in the catabolism of catecholamines, and its induction may signify that an important function of sleep is to prevent the uninterrupted activity of the noradrenergic system.

\section{ACKNOWLEDGMENTS}

This work was carried out as part of the experimental neurobiology program at The Neurosciences Institute, which is supported by Neurosciences Research Foundation. The Foundation receives major support for this program from Novartis Pharmaceutical Corporation. We thank Glen A. Davis, Marijo C. Gallina, and Donald F. Robinson for their expert contribution.

\section{REFERENCES}

Aston-Jones G, Bloom FE (1981a): Activity of norepinephrine-containing locus coeruleus neurons in behaving rats anticipates fluctuations in the sleep-waking cycle. J Neurosci 1:876-886

Cape EG, Jones BE (2000): Differential modulation of high-frequency $\gamma$-electroencephalogram activity and sleep-wake state by noradrenaline and serotonin microinjections into the region of cholinergic basalis neurons. J Neurosci 18:2653-2666

Cirelli C, Pompeiano M, Tononi G (1995): c-Fos expression in the rat brain after sleep deprivation. J Sleep Res 4:92106

Cirelli C, Pompeiano M, Tononi G (1996): Neuronal gene expression in the waking state: a role for the locus coeruleus. Science 274:1211-1215

Cirelli C, Tononi G (1998): Differences in gene expression between sleep and waking as revealed by mRNA differential display. Mol Brain Res 56:293-305

Cirelli C, Tononi G (1999): Changes in gene expression in the cerebral cortex of rats after short-term and long-term sleep deprivation. Sleep 22 (Suppl 1):113

Cirelli C, Tononi G (2000a): Gene expression in the brain across the sleep-waking cycle. Brain Res 885:303-321

Cirelli C, Tononi G (2000b): Differential expression of plas- ticity-related genes in waking and sleep and their regulation by the noradrenergic system. J Neurosci 20:91879194

Cirelli C, Tononi G (2000c): On the functional significance of c-fos induction during the sleep/waking cycle. Sleep 23:453-469

Drummond SP, Brown GG, Gillin JC, Stricker JL, Wong EC, Buxton RB (2000): Altered brain response to verbal learning following sleep deprivation. Nature 403:655-657

Heynen AJ, Quinian EM, Bae DC, Bear MF (2000): Bidirectional, activity-dependent regulation of glutamate receptors in the adult hippocampus in vivo. Neuron 28: $527-536$

Horne JA (1988): Why we sleep. The functions of sleep in humans and other mammals. Oxford, Oxford University Press.

Jacobs BL, Fornal CA (1999): Activity of serotonergic neurons in behaving animals. Neuropsychopharmacol 21: 9S-15S

Kuhl D, Kennedy TE, Barzilai A, Kandel ER (1992): Longterm sensitization training in Aplysia leads to an increase in the expression of $\mathrm{BiP}$, the major protein chaperon of the ER. J Cell Biol 19:1069-1076

Maquet P (1995): Sleep function(s) and cerebral metabolism. Behav Brain Res 69:75-83

McGinty DJ, Harper RM (1976): Dorsal raphe neurons: depression of firing during sleep in cats. Brain Res 101: 569-575

Milner FD, Sutcliffe JG (1983): Gene expression in rat brain. Nucleic Acid Res 11:5497-5520

Pompeiano M, Cirelli C, Tononi G (1994): Immediate-early genes in spontaneous wakefulness and sleep: Expression of c-fos and NGFI-A mRNA and protein. J Sleep $\operatorname{Res}$ 3:80-96

Ramm P, Frost BJ (1983): Regional metabolic activity in the rat brain during sleep-wake activity. Sleep 6:196-216

Shaw PJ, Cirelli C, Greenspan RJ, Tononi G (2000): Correlates of sleep and waking in Drosophila Melanogaster. Science 287:1834-1837

Sheng M, Greenberg ME (1990): The regulation and function of c-fos and other immediate early genes in the nervous system. Neuron 4:477-485

Tononi G, Cirelli C, Shaw PJ (2000): The Molecular correlates of sleep, waking, and sleep deprivation. In Borbély A, Hayaishi O, Sejnowski TJ, Altman JS (eds), Human Frontier Workshop VIII, The Regulation of Sleep. Strasbourg, HFSP, pp. 155-167.

Wong-Riley MTT, Mullen MA, Huang Z, Guyer C (1997): Brain cytochrome oxidase subunit complementary DNAs: isolation, subcloning, sequencing, light and electron microscopic in situ hybridization of transcripts, and regulation by neuronal activity. Neuroscience 76: 1035-1055 